\title{
Challenges Facing Libyan Pharmacists During the Drug Dispensing Process
}

\author{
Arwa Benkhaial $^{1 *}$, Ghada Elfalah ${ }^{1}$, Rania Elshalmane ${ }^{2}$, Najah Alzuway $^{2}$, \\ Amal Elbaba $^{2}$,Arwa Elfarjani $^{2}$ and Adel Elorfi ${ }^{2}$ \\ ${ }^{I}$ Department of Pharmacology and Toxicology, Faculty of Pharmacy, University of Benghazi, Benghazi \\ ,Libya \\ ${ }^{2}$ Department of Basic Medical Sciences, Faculty of Pharmacy, University of Benghazi, Benghazi ,Libya
}

Received: 24 February 2019/ Accepted: 30 June 2019

Doi: https://doi.org/10.54172/mjsc.v34i2.75

\begin{abstract}
Pharmacists are supposed to deliver services, like counseling, dispensing, and managing patients care plans. During daily routine they face problems that can hinder their job, e.g., work overload stress, or unorganized drug shelves, and unclear written prescription, which may lead to errors during drug dispensing. These errors are traumatic for the pharmacist and patient; therefore, it is crucial to reduce them and any circumstances that leads to them. In this study, we aimed to study some of the problems that face Libyan pharmacists in their daily routine and prevent them from performing their main roles as community pharmacists. An online cross-sectional survey of pharmacists in Libya was conducted over a period of four months. This online questionnaire was built using the "Google forms" application and was distributed to participants using social network groups of pharmacists. 182 pharmacists responded to this questionnaire. Almost (45\%)of the respondents found it difficult to educate patients on their medicines and any related health issues. Meanwhile, the bulk majority (82\%) stated that the major problem that faced them was getting a prescription written with very bad handwriting. About (59.4\%) of the responding pharmacists stated that they did not have enough time to educate patients about their medications during drug dispensing. In conclusion, this study reveals some of the main challenges that face pharmacists during their daily work. Generally, it shows that it is necessary to make pharmacists aware of social and environmental factors that may complicate their work. This can be done by educating practicing pharmacists about "good pharmacy practices" through workshops and continuous learning programs. Additionally, regulating authorities should also play a role in establishing policies and laws that regulate the design of retail pharmacies.
\end{abstract}

Keywords: Drug Dispensing, Dispensing errors, Pharmacy practice

\section{INTRODUCTION}

In the recent years, the pharmacists' role has changed from just compounding and dispensing pharmaceutical products to managing therapy plans, and this role has evolved to include: patient education, patient counseling, and community services (Wiedenmayer et al., 2006). Pharmacists also act as first responders, providing clinical advice to over-the-counter (OTC) relief, which helps in decreasing unnecessary emergency room visits for common conditions
(APHA, 2006). In addition, They are responsible for ensuring the quality of pharmaceuticals/medicines supplied to patients as per the government policies/regulation and patients, pharmaceutical education including counseling of patients (Thamby \& Subramani, 2014).

In order to ensure the safe and correct use of medicine, pharmacists should be able to freely communicate with patients so they can respond to symptoms, discuss patient health-

\footnotetext{
*Corresponding Author: Arwa Benkhaial arwa.benkhaial@uob.edu.ly, Department of Pharmacology and Toxicology, Faculty of Pharmacy, University of Benghazi, Benghazi,Libya.
} 
related and social problems that have an impact on health status, and empower individuals to be active in health promotion and preservation (Kerr et al., 2017) since the well-informed patients are more likely to use their medications correctly. Additionally, the pharmacist's intervention in the provision of advice on medicines improves medicine safety (Azzopardi, 2010).

Dispensing medications to patients is a complex process, that happens under the supervision of the pharmacist (National Patient Safety Agency, 2007). During the drug dispensing, pharmacists are faced with some challenging tasks that need to be coordinated and performed together with accuracy. Some of these tasks are including; dispensing the correct medicines, checking other medicines e.g., for drug interactions, and patient advice (WHO).

Errors can arise at any stage during the dispensing process. if the medication dispensed to a patient is inappropriate (e.g. due to incorrect interpretation of the prescription), this can be called a "Dispensing error"(Azzopardi, 2010). Dispensing errors include any inconsistencies or deviations from the prescription order, such as dispensing the incorrect drug, dose, dosage form, wrong quantity, or inappropriate, incorrect, or inadequate labelling. Also, confusing or inadequate directions for pharmaceutical preparation use, incorrect or inappropriate preparation, packaging, or storage of medication prior to dispensing are considered to be errors (Szeinbach, SeoaneVazquez, Parekh, \& Herderick, 2007). Another type of errors is dispensing the right drug to the wrong patient. These errors when not detected and corrected prior to the patient leaving the pharmacy may lead to sub-optimal outcomes of treatment for the patient, or even deadly damage (James et al., 2009). Dispensing the wrong drug, which often involve the substitution of another drug with a sound-alike name, accounted for $43.8 \%$ of all claims paid as a result of the injuries caused (Webb, 2015).
Many of the reasons for dispensing errors remain anecdotal. Noise, distractions, poor packaging, and workload have all been put forward as causes of errors. Many errors are blameless, and effective risk management requires a reporting culture (Al-Arifi, 2014). For example, a change in packaging by a manufacturer could trigger a group of dispensing errors. In an individual pharmacy, the pharmacist in control would only experience a single error in isolation. Across a wider sample of pharmacies, multiple errors may highlight problems which can be rectified to prevent future occurrences (Cox \& Marriott, 2000).

The most common factors that are associated with dispensing errors including high workload, low-staff numbers, a mix-up of lookalike/sound-alike drugs, and dispensary staff's lack of knowledge/experience (Aldhwaihi, Schifano, Pezzolesi, \& Umaru, 2016). Also in a study that surveyed pharmacists attitudes toward dispensing errors in a community pharmacy settings in Saudi Arabia, the major factors associated with dispensing errors were not having a pharmacist assistant (82.2\%), high workload (72.5\%) (Al-Arifi, 2014), pressure to work too quickly particularly when there is a long line of patients, patient misidentification (Webb, 2015), and patient knowledge deficits (Azzopardi, 2010). However, the pharmacist may face a lot of problems that can restrict his/her work such as stress due to work overload, crowded pharmacy, or unorganized drug shelves which may lead to errors during the dispensing process. Hence, this study tries to detect some of the main problems that face Libyan pharmacists during their daily work that may hinder the efficiency of their job.

This study had the aim to:

1. Recognize some of the problems facing Libyan pharmacists in private and hospital pharmacies that prevent them from performing their main roles.

(C) 2019 The Author(s). This open access article is distributed under a CC BY-NC 4.0 license. ISSN: online 2617-2186 print 2617-2178 
2. Detect the awareness of Libyan pharmacists about these problems that may affect the dispensing process and can lead to errors in it.

\section{MATERIALS AND METHODS}

A preliminary draft of the questionnaire was piloted on convenience of 12 practicing pharmacists to check for readability, understanding, question design, and the length of the questionnaire. Based on the result of this pilot study, the questionnaire was used with some modifications, and the final questionnaire was distributed to participants. An online questionnaire for Libyan pharmacists was conducted over a period of 2 months. Because of the low response rate, the questionnaire was further redistributed as a second phase to increase the response rate for another 2 months.

The questionnaire was constructed using the "Google forms" (Google $C$, 2018) application. This application collected the data and analyzed them. The questionnaire consisted of a series of questions where most of them were of closed multiple choice type. The questionnaire included 12 items about the pharmacist's role in the community and the challenges they face in accomplishing this role. Demographic information of the pharmacist was collected too. The first five questions were about age, gender, degree, experience, and the sector they work in. The rest of the questions asked about many aspects regarding the difficulties pharmacists find while practicing their role, problems they face while dispensing medications, circumstances that help them in their work, what prevents them from educating the patient about his/her medicine, what additional information they may require during dispensing, if they would hesitate to dispense an incomplete prescription, and what information would make them consider not dispensing the medication, if incomplete. The survey responses were treated, and the data from all the respondents were analyzed by "Google forms". Descriptive statistics, including percentages and frequency distribution, was calculated for each of the variables.

\section{RESULTS}

182 respondents have responded to this questionnaire. The majority of the respondents were young adults (age group of 20-30 years) contributing about $79.7 \%$ of the respondents, while older age groups (older than 50 years) were only $1.6 \%$. About $62 \%$ of the respondents were females, while approximately $38 \%$ were males. The vast majority of the respondents had a Bachelor degree (97.8\%). More than half of respondents had a work experience of 5-10 years (65\%), and about $25 \%$ had experience of work from 5-10 years. Approximately $64 \%$ of the responding pharmacists worked in the private sector and about $32 \%$ worked in public health facilities. The whole demographic data are shown in Table 1.

Table (1). Socio-demographic data.

\begin{tabular}{lc}
\hline \multicolumn{1}{c}{ Parameter } & Percentage(\%) \\
\hline Age (years) & \\
$20-30$ & $79.7 \%$ \\
$30-40$ & $16.3 \%$ \\
$40-50$ & $2.2 \%$ \\
more than 50 & $1.6 \%$ \\
Gender & \\
Male & $37.9 \%$ \\
Female & $62.1 \%$ \\
Degree & \\
Bachelor degree & $97.8 \%$ \\
Other. & $2.2 \%$ \\
Work Experience & \\
$5-10$ years & $69 \%$ \\
$10-15$ years & $25.4 \%$ \\
15-20 years & $2.8 \%$ \\
more than 20 years & $2.8 \%$ \\
Work Sector & \\
Private Pharmacy & $64.3 \%$ \\
Public Health Facilities & $31.9 \%$ \\
Both & 3.8 \\
\hline \hline
\end{tabular}

Opinions were sought on which of the pharmacists' role they found more difficult to ful- 
fill, and $44.5 \%$ of the respondents found it difficult to educate patients on their medicines and other related health issues. Around $29 \%$ of the responding pharmacists exclaimed finding it hard to participate in the encouragement and improvement of patients health, while only $11.8 \%$ found it difficult to supply patients with medicines and medical appliances.

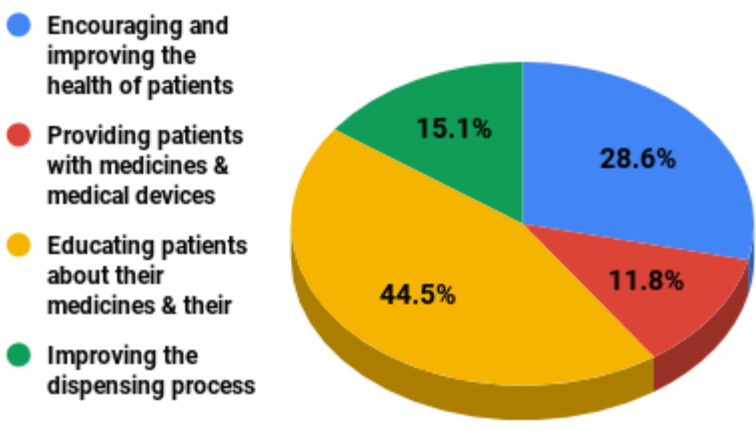

Figure(1). The distribution of respondents when asked about the role of pharmacists they find difficult to fulfill.

Similarly, opinions were sought on which problems they face while dispensing drugs, and the bulk majority $(81.7 \%)$ said that getting a prescription written with very bad handwriting was considered the major difficulty they would face while doing their job. Only a minority of the respondents stated that drugs with similar names and different generics posed a challenge for them in their daily work, with $(3.3 \%)$ and $(1.7 \%)$ respectively. The different problems that pharmacist face with the respective percentages are shown in Figure2.

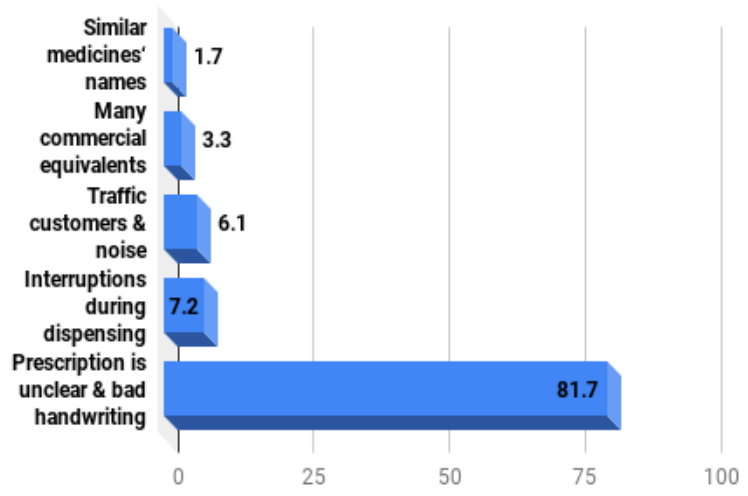

Figure (2). The distribution of respondents when asked about the problems they face while dispensing drugs.
When the respondents were asked "What would help them and support their work?", $39.3 \%$ stated that the design and arrangement of the pharmacy would support their work while about $24.7 \%$ thought that having computer programs or pharmaceutical application would assist them in their work.

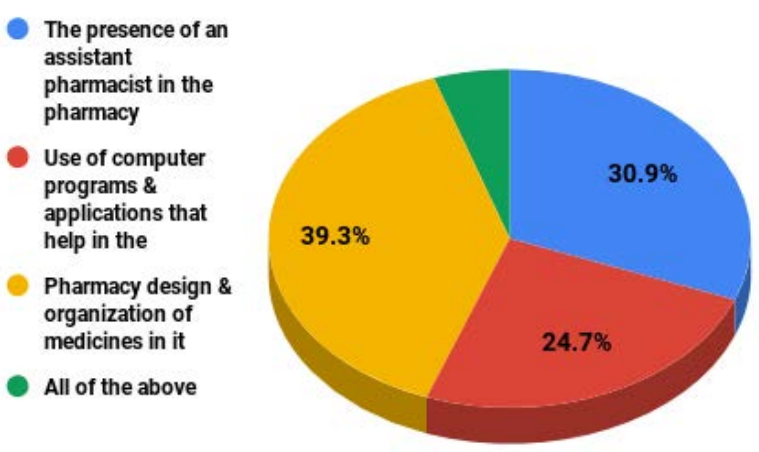

Figure (3). The distribution of respondents when asked about factors that support their work.

When asked about the difficulties that pharmacists face while educating the patients about their medications, the bulk majority (59.4\%) of respondents found it difficult to have enough time to educate the patients about their medications. Approximately $21.1 \%$ stated that the design of the pharmacy did not help them have the needed privacy in order to educate the patient on his/her medication.

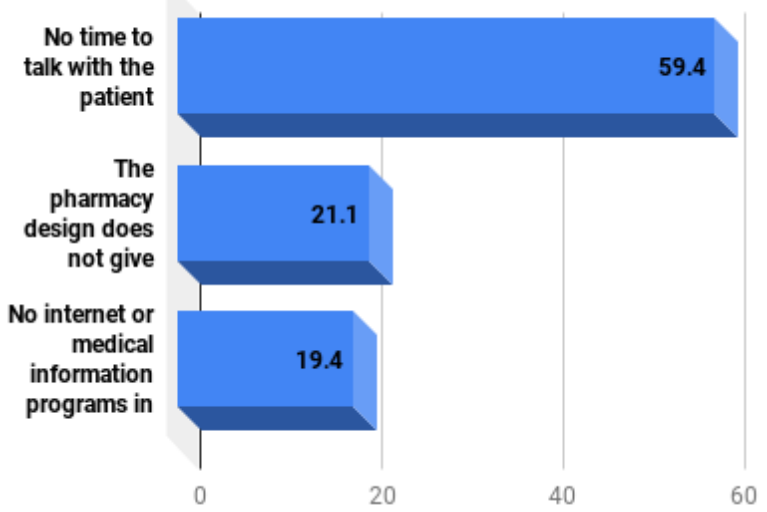

Figure (4).The distribution of respondents when asked about environmental factors that make the process of patient counseling difficult.

(C) 2019 The Author(s). This open access article is distributed under a CC BY-NC 4.0 license. ISSN: online 2617-2186 print 2617-2178 
Checking for further medication before dispensing is an important step, accordingly, the majority $(66.5 \%)$ of the respondents in this study did not miss that. But about $14.5 \%$ of the respondents would not ask any questions during the dispensing process. Table 2. shows the distribution of the respondents to the question "What further information they ask the patient before dispensing a medication?".

Table (2). The distribution of respondents when asked about the additional information that they need to know from the patient during dispensing.

\begin{tabular}{lc}
\hline \hline Questions asked before dispensing & Percentage(\%) \\
\hline any other medications & $66.5 \%$ \\
any allergies & $19 \%$ \\
No questions are asked & $14.5 \%$ \\
\hline \hline
\end{tabular}

$74.4 \%$ of the respondents answered "Yes" to the question "Would you hesitate to dispense an incomplete prescription?", whereas approximately, $12 \%$ said that they would not hesitate to do that at all.

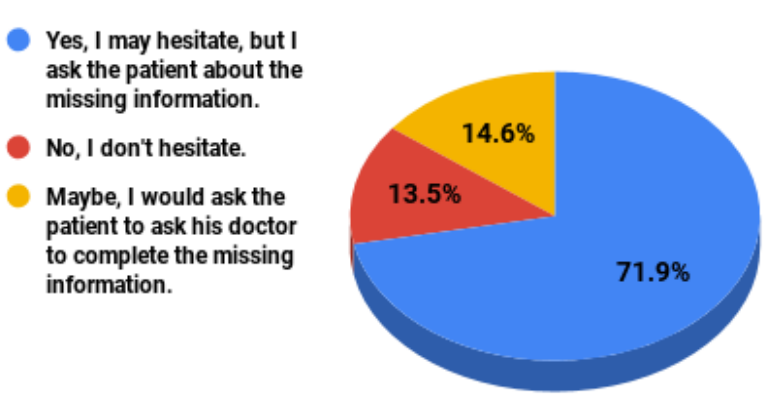

Figure (6). The distribution of responding pharmacists when asked if they would hesitate to dispense an incomplete prescription.

Table 3. The distribution of respondents when asked about the information that may let the pharmacist not dispense the medicine.

\begin{tabular}{lc}
\hline \hline $\begin{array}{l}\text { Reason for not dispensing medi- } \\
\text { cine }\end{array}$ & Percentage $(\%)$ \\
\hline $\begin{array}{l}\text { The name, age and address of the } \\
\text { patient }\end{array}$ & 9.6 \\
The name of medicine \& dose & 40.9 \\
The name \&address of the doctor & 1.7 \\
The dosage form of drug & 17.4 \\
\hline \hline
\end{tabular}

\section{DISCUSSION}

Pharmacists are in charge of medication dispensing, and they often deal directly with patients with health conditions and treatment that are closely related to their personal and social status (Deans, 2010). During this critical process, they face a lot of challenges that may hinder them from performing these tasks efficiently.

In our study, we tried to detect the difficulties that face pharmacists in their daily work especially during drug dispensing in pharmacy, and prevent them from performing their job properly, and may lead to errors in their main daily task.

One of the essential roles of pharmacists is to educate the patients on medication use and other issues related to their health. In our study, about $45 \%$ of the responding pharmacists found it difficult to fulfill this task. This can be attributed to many reasons, such as lack of time, lack of privacy, and the design of the dispensary area. These factors were considered by the respondents as the main causes that jeopardize having a good environment for patient education. They were also considered among the factors contributing to dispensing errors according to a Saudi study that studied the attitude of pharmacists toward dispensing errors(Al-Arifi, 2014).

A major finding in our study is that approximately $82 \%$ of responding pharmacists considered getting a prescription with very bad handwriting as the major problem that they face in their daily work. It is well known that illegible, inaccurate prescriptions are sources of errors during drug dispensing. Reports of injuries, secondary to poor handwriting, continued to accumulate in the regulatory literature to the point that the Institute for Safe Medication Practices (ISMP) published a call to action to eliminate handwritten prescriptions by 2003 (Teichman \& Caffee, 2002). Actually, pharmacists considered improving the illegibility of the

(C) 2019 The Author(s). This open access article is distributed under a CC BY-NC 4.0 license.

ISSN: online 2617-2186 print 2617-2178 
prescriptions as one of the most appreciated factors in decreasing dispensing errors and improving doctors' handwriting (Al-Arifi, 2014). Nowadays, the electronization of prescription writing in most developed and some developing countries has become a must.

Most of the respondents emphasized the importance of the design of the pharmacy and the organization of the dispensary. This factor has also been stressed in the literature (Nair, Kappil, \& Woods, 2010), and it seems to be a point that needs to be further scrutinized on a national basis.

As known, patient education during medication dispensing is the main role of pharmacists in their communities, but it seems that Libyan pharmacists find it hard to carry out this task. This was evident with $59.4 \%$ of the respondents claiming that "they do not have enough time for patient education". This seems to be a problem that faces pharmacists not only nationally but internationally (Berger, 2009).Another factor that has been highlighted in this regard was "not having privacy for patient education", which leads us back to the previously mentioned point of pharmacy design. In this context, it seems that pharmacies in Libya lack the special required aspects that help pharmacists to perform their job efficiently (Abood, 1996).

Regarding the questions to be asked about any further information that the pharmacist need for effective patient education, Libyan pharmacists seemed to have an acceptable knowledge about good pharmacy practice, with almost $67 \%$ asking about other medication, and $19 \%$ asking about any allergies. Surprisingly, around $15 \%$ seemed to not practice this at all, which implies a negative attitude towards this practice from some of the responding pharmacists.

An incomplete prescription renders the pharmacist confused, which makes him/her hesitating to dispense it. This was the case with about $72 \%$ of the respondents, and some of them would try to complete the missing information from the patient or even the prescriber. Typically, the two most important information that would make the dispensing impossible without were "drug name and dose" and "the dosage form" with $41 \%$ and $17.4 \%$, respectively.

Generally, an online questionnaire has the advantage that the respondents feel more comfortable answering the questions anonymously because, in the preparation phase of the questionnaire, we had the problem that the interviewed pharmacists were hesitant to answer the questionnaire, even though they were assured that the data was anonymously handled. Also, an online survey is less time consuming and requires fewer logistics.

This study had numerous disadvantages, firstly being an online survey, where we could not be sure about the credibility of the answers, e.g., some of the respondents could not be pharmacists at all. Secondly, the survey was formulated with closed-ended questions, which make it have a lower validity rate than other question types, e.g. open-ended questions. Additionally, survey question-answer options could lead to unclear data because certain answer options may be interpreted differently by respondents. An important drawback of this study is the small number of respondents, which may render the results either not representative, or not conclusive.

\section{CONCLUSION}

This study can be considered as a priori that approached an important topic about pharmacy practice, that is the challenges and difficulties that face pharmacists during their daily work. That, in turn, may lead to errors during drug dispensing, leading to possible unwanted events. Thus it is imperative for pharmacists to be aware of social and environmental factors that may complicate their work. This can be done by educating practicing pharmacists about "good pharmacy practices" through workshops, leaflets, and/or continuous learn- 
ing programs. Additionally, regulating authorities should also play a role by establishing policies and laws that regulate the design of retail pharmacies. Also, data on dispensing errors should be gathered and reviewed so that risk-reduction strategies can be developed to assure the quality and safety of patient care.

\section{REFERENCES}

Abood, R. (1996). Errors in pharmacy practice. Us Pharm, 21(3), 122-132.

Al-Arifi, M. N. (2014). Community pharmacists' attitudes toward dispensing errors at community pharmacy setting in Central Saudi Arabia. Saudi Pharmaceutical Journal, 22(3), 195-202.

Aldhwaihi, K., Schifano, F., Pezzolesi, C., \& Umaru, N. (2016). A systematic review of the nature of dispensing errors in hospital pharmacies. Integrated pharmacy research \& practice, 5,1 .

American Public Health Association (APHA) (Nov 08 2006). https:// www.apha.org/ policies-and-advocacy/public-healthpolicy-statements/ policydatabase /2014/07/07/13/05/the-role-of-thepharmacist-in-public-health.(Accessed 9.12.2018)

Azzopardi LM. (2010). Lecture Notes in Pharmacy Practice, Pharmaceutical Press, ISBN: 0853699496, 9780853699491

Berger, B. A. (2009). Patient-centered care: it's about time. American journal of pharmaceutical education, 73(5), 91.

Cox, A., \& Marriott, J. (2000). Dealing with dispensing errors. The Pharm J, 264, 724.
Deans, Z. (2010). Ethics in pharmacy practice: Pharmacy Practice Research Trust London.

James, K. L., Barlow, D., McArtney, R., Hiom, S., Roberts, D., \& Whittlesea, C. (2009). Incidence, type and causes of dispensing errors: a review of the literature. International journal of pharmacy practice, 17(1), 9-30.

Kerr, A., Strawbridge, J., Kelleher, C., Mertens, F., Pype, P., Deveugele, M., \& Pawlikowska, T. (2017). How can pharmacists develop patient-pharmacist communication skills? A realist review protocol. Systematic reviews, 6(1), 14.

Lecture Notes in Pharmacy (2010). Practice by Lilian M Azzopardi Published by the Pharmaceutical Press, First published. 8, (39-41).

Nair, R., Kappil, D., \& Woods, T. (2010). Ten strategies for minimizing dispensing errors. Pharmacy Times.

National Patient Safety Agency (NPSA), (2007). Design for Patient Safety. A Guide to the Design of the Dispensing Environment, London,

Szeinbach, S., Seoane-Vazquez, E., Parekh, A., \& Herderick, M. (2007). Dispensing errors in community pharmacy: perceived influence of sociotechnical factors. International Journal for Quality in Health Care, 19(4), 203-209.

Teichman, P. G., \& Caffee, A. E. (2002). Prescription writing to maximize patient safety. Family practice management, 9(7), 27.

Thamby, S. A., \& Subramani, P. (2014). Seven-star pharmacist concept of WHO. Journal of Young Pharmacists, 6(2), 1. 
Webb, J. (2015). Pharmacy dispensing errors: Claims study emphasizes need for systematic vigilance. Drug Topics, Modern Medicine Network.

Wiedenmayer, K., Summers, R. S., Mackie, C. A., Gous, A. G., Everard, M., Tromp, D., \& Organization, W. H. (2006). Developing pharmacy practice: a focus on patient care: handbook: Geneva: World Health Organization.

World Health Organization Archives http://archives.who.int/PRDUC2004/R DUCD/Sesson Guides/role of dispens ers in rational d.htm (Accessed 2018.Dec.8) 


\section{الصعويات التي تواجه الصيادلة الليبيين أثناء عملية صرف الدواء}

أروى بن خيال***، غادة الفلاح'، رانيا الثلماني ²، نجاح الزوي²، أمل البابا2، أروى الفرجاني² وعادل العرفي²

1 قسم علم الأدوية والسموم، كلية الصيللة، جامعة بنغازي ، بنغازي ، ليييا

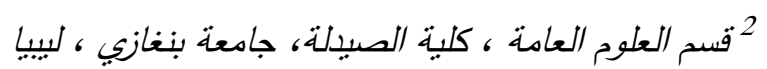

تاريخ الاستلام: 24 فبراير 2019 / تاريخ القبول: 30 يونيو 2019 https://doi.org/10.54172/mjsc.v34i2.75:Doi

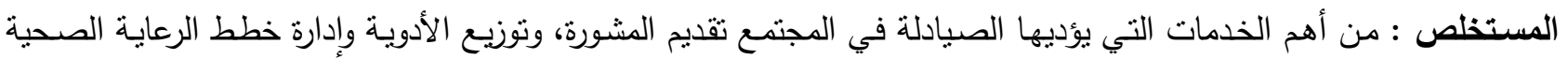

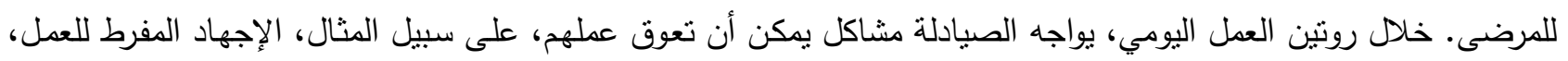

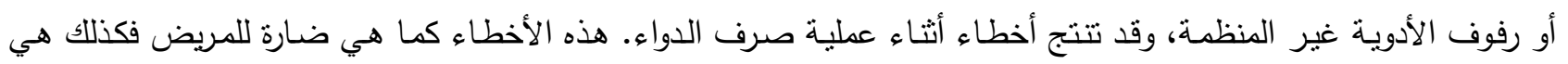

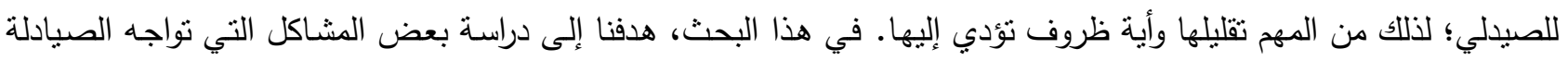

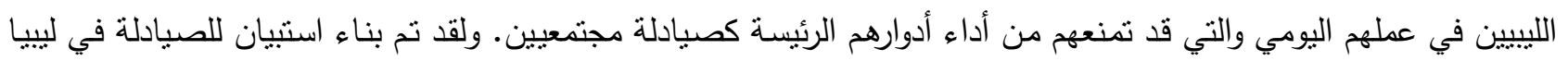

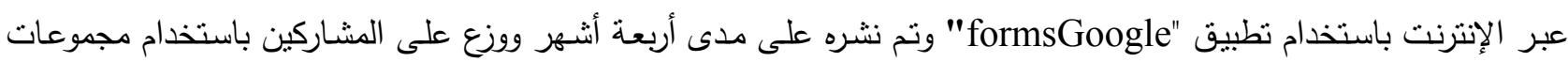

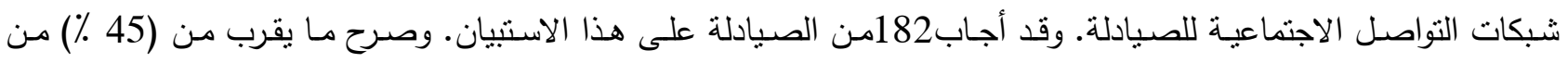

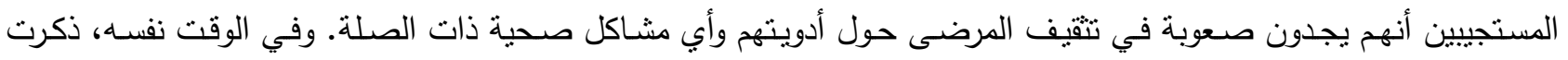
الغالبية العظمى منهم (82٪) أن المشكلة الرئيسة التي تواجهم هي "ورود وصفات مكتوبة بخط سيئ للغاية". وصرّح (59.4٪)

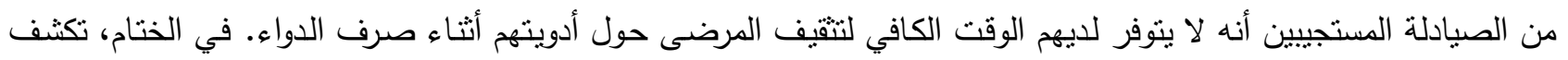

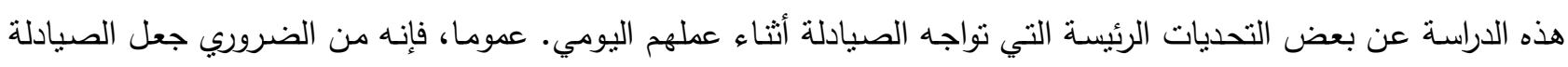

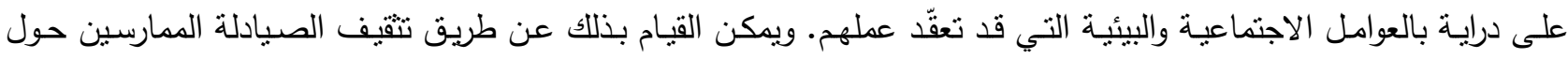

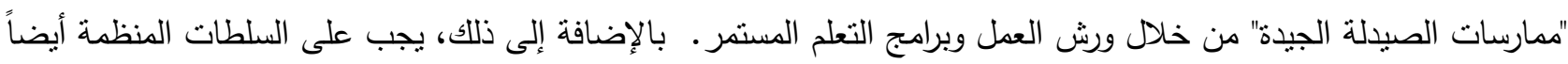
أن تؤدي دوراً في وضع السياسات والقوانين التي تتظم تصميم صيدليات البيع بالتجزئة.

الكلمات المفتاحية : صرف الدواء، الأخطاء أثثاء عملية الصرف، الممارسة الصيدلية. 